Special Issue of the 6th International Congress \& Exhibition (APMAS2016), Maslak, Istanbul, Turkey, June 1-3, 2016

\title{
Fabrication of Functional Graded Al2124 Composite Reinforced with $\mathrm{Al}_{2} \mathrm{O}_{3}$ Particles
}

\begin{abstract}
F. ÇALIŞKAN ${ }^{a, *}$, S. CÖMERT ${ }^{a}$ AND E. KOCAMAN ${ }^{b}$
${ }^{a}$ Sakarya University, Faculty of Technology, Department of Metallurgical and Materials Engineering ${ }^{b}$ Bulent Ecevit University Faculty of Engineering Department of Metallurgical and Materials Engineering

The composite materials formed by powder metallurgy are mostly used in industry due to their excellent properties such as low density, high strength, and hardness. The aim of this study is to produce functional graded $\mathrm{Al}$ material reinforced with macro-sized $\mathrm{Al}_{2} \mathrm{O}_{3}$. To fabricate the aluminum matrix composite, commercial $\mathrm{Al} 2124$ aluminum alloy powder (from Gürel Makina), which is used in aerospace and defense industries, was chosen as a matrix material. Powder metallurgy was used to produce the functional graded material because it allows an easy incorporation of reinforcement phase into the matrix. The sintered samples were characterized using optical microscopy, SEM, and X-Ray diffraction analysis. The results show that functional graded material structure and the transition interlayers were achieved by the presented process.
\end{abstract}

DOI: 10.12693/APhysPolA.131.437

PACS/topics: 81.05.-t

\section{Introduction}

Metal-matrix composites (MMCs) were already known in the late 1950s and early 1960s, which then have been called the materials of the future [1]. MMCs have applications in the energy technology, automotive industry, defense, space and various other industries because of their impressive strength, fracture toughness, low density, high stiffness, high thermal conductivity, thermal shock resistance, improved strength, and high wear resistance at room temperature [1-3]. Among all ceramic reinforced metal composites, the $\mathrm{Al}-\mathrm{Al}_{2} \mathrm{O}_{3}$ pair has came forward because of its superior properties and has been one of the most intensively studied systems $[3,4]$. The metal-ceramic functional graded materials (FGMs), which are compositionally graded from a ceramic phase to a metal phase, can be designed to improve thermal properties, corrosion resistance, and the mechanical strength. The processes for functionally graded $\mathrm{Al}-\mathrm{Al}_{2} \mathrm{O}_{3}$ composite production are based on a variation of conventional processing methods [5, 6]. Powder metallurgy $(\mathrm{PM})$ method is one of the most commonly employed techniques due to its wide range control on composition and microstructure and the shape forming capability. Powder metallurgy is used to produce functionally graded materials. PM technique gives rise to a stepwise structure [7-9]. The main driving force to conduct this work was to produce functionally graded $\mathrm{Al}_{2} \mathrm{O}_{3}-\mathrm{Al}$ composites with extraordinary properties when compared with traditional $\mathrm{Al}_{2} \mathrm{O}_{3}-\mathrm{Al}$ couples.

\section{Experimental}

This study presents fabrication and characterization of $\mathrm{FGM} \mathrm{Al} / \mathrm{Al}_{2} \mathrm{O}_{3}$ containing various reinforcement layers,

*corresponding author; e-mail: fcaliskan@sakarya.edu.tr
0-10 wt.\% and 0, 5, 10 and 15 wt.\%, using powder metallurgy manufacturing process. Schematic demonstration of the uniaxial die pressing process for the FGM is given in Fig. 1. Figure 2 shows a gradient of the fraction for the FGM composite.

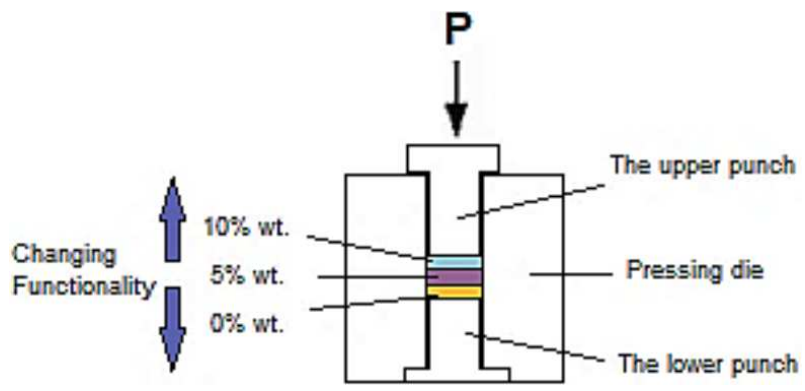

Fig. 1. Schematic of the uniaxial die pressing process.

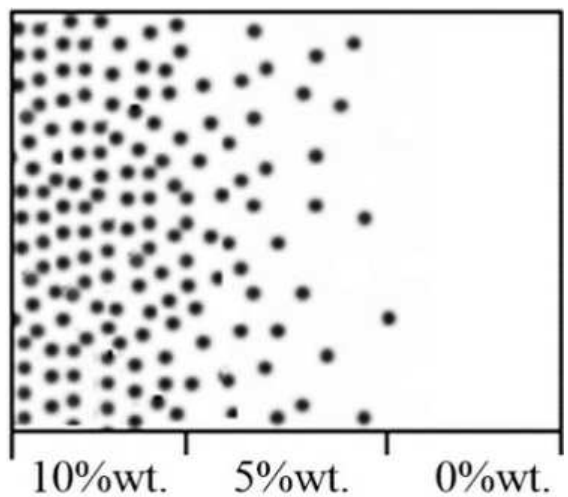

Fig. 2. Gradient of fraction for the FGM composite.

Powder mixtures were prepared in four different molar ratios to determine the optimum composition. Subsequently, the mixture was milled by attritor milling, to ensure the increase of effectiveness of distribution and the decrease of $\mathrm{Al}$ particle size. The green samples were 
obtained by pressing under $400 \mathrm{MPa}$ and sintered at $>630^{\circ} \mathrm{C}$ in flowing Ar. To investigate the microstructure of the interlayer transition zone, all samples were embedded in bakelite, then ground and polished.

XRD (Rigaku Dimaks 2200) was used to reveal the chemical composition. The densities of the sintered samples were measured using the Archimedes principle in distilled water. Scanning electron microscopy (SEM) (JEOL5600 ) was performed to examine densification and particle distribution.

\section{Results and discussion}

\subsection{Microstructural examination and phase analysis}

Diffractograms of the powder Al (ICDD 01-071-4622) is presented in Fig. 3. The XRD pattern of the starting Al 2124 powder in Fig. 3 shows that all peaks belong to a regular $\mathrm{Al}$ phase. The peaks are in accord with previous reports $[10,11]$. Because $\mathrm{Al}$ alloy was not heat treated, no secondary phase is seen in Fig. 3. Consequently, the resulting product is a mono-phase metal.

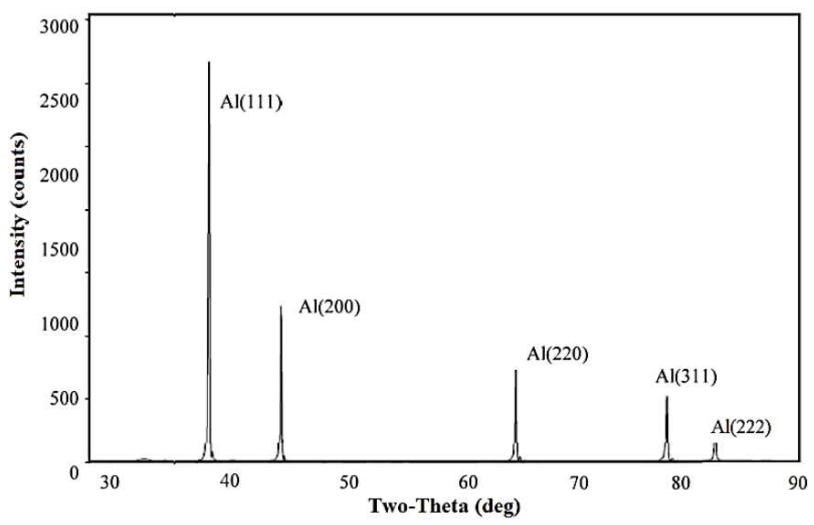

Fig. 3. XRD pattern of $\mathrm{Al} 2124$ used as the matrix phase.

The SEM micrographs of the sintered FGM composites with 5 wt. $\%$ of $\mathrm{Al}_{2} \mathrm{O}_{3}$ and 10 wt. $\%$ of $\mathrm{Al}_{2} \mathrm{O}_{3}$ layers are given in Figs. 4 and 5. Microstructural studies have confirmed that all of the sintered FGMs have a quite homogeneous distribution of alumina particles and that no contact appears between particles in the matrix. Full densification has not been observed in samples containing higher ceramic particle ratios. This behavior can be explained by the formation of micro-pores and the presence of pore region in the matrix between particles because of contact. The amount of small ceramic particles dispersing in microstructure has increased with the increasing amount of $\mathrm{Al}_{2} \mathrm{O}_{3}$ particles reinforcement. This phenomenon is seen in the difference between Fig. 4 and Fig. 5 . These are considered as an advantage, because they are retarding the matrix erosion. The other indicator of this phenomena is the color changing in SEM pictures. Their colors have changed with the increasing reinforcement ratio from white to dark (Figs. 4 and 5). Another finding is

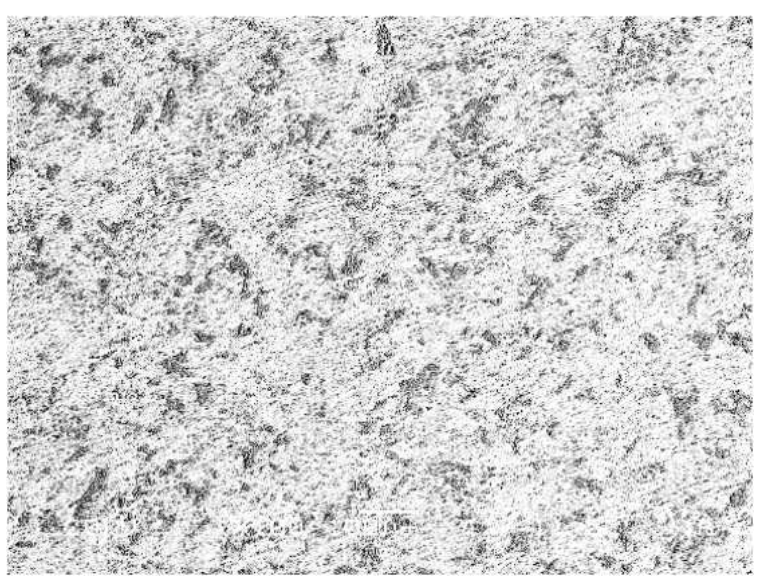

Fig. 4. SEM micrograph of the 5 wt. $\% \mathrm{Al}_{2} \mathrm{O}_{3}$ layer in the FGM.

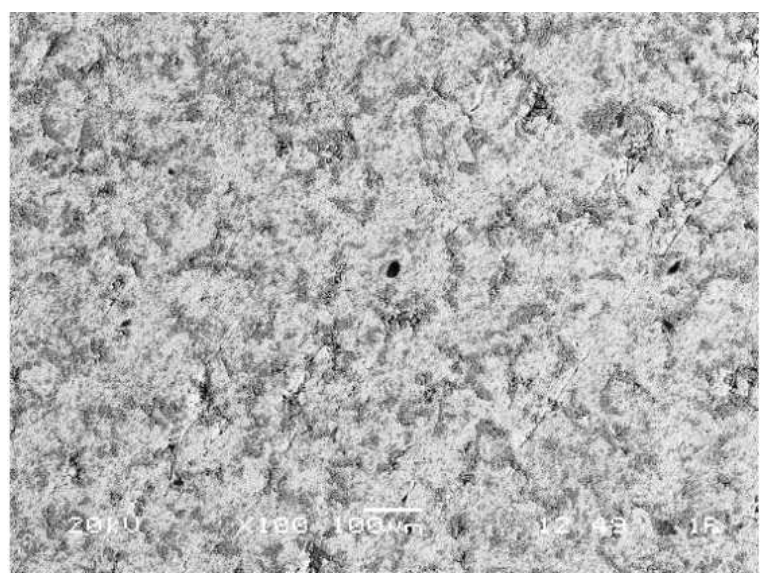

Fig. 5. SEM micrograph of the 10 wt. $\% \mathrm{Al}_{2} \mathrm{O}_{3}$ layer in the FGM.

that reinforcements provide the evolution to fresh oxidefree surface, destroying the grain boundaries during cold pressing. Therefore, the increment in the amount of alumina has caused the disappearance of the more visible grain boundary in matrix alloy.

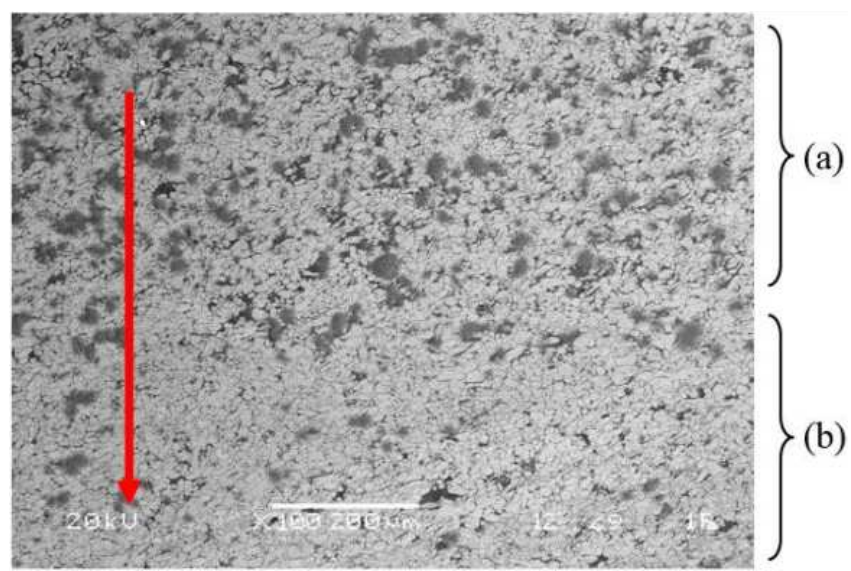

Fig. 6. Transition zone from (a) 10 wt. $\% \mathrm{Al}_{2} \mathrm{O}_{3}$ reinforced material to (b) Al 2124 alloy. 
A critical factor in the FGM processing is a sharp transition from layer to layer, in PM method. As is seen in Fig. 6, a slight transition was achieved in the present study. While region in Fig. 6a shows layer reinforced with 10 wt.\% of $\mathrm{Al}_{2} \mathrm{O}_{3}$, in Fig. $6 \mathrm{~b}$ region there is only $\mathrm{Al} 2124$ matrix alloy. EDS analysis was carried out along the arrow direction in Fig. 6. EDS analysis results are given in Fig. 7. To reveal this transition, the contents of oxygen from alumina and aluminum were studied using linear EDS scan. It shows that while region (a) contains large amount of alumina particles, region (b) does not contain almost any alumina particles. Outside region (a), while peaks of oxygen have decreased, there is an obvious simultaneous increase in peaks of $\mathrm{Al}$.

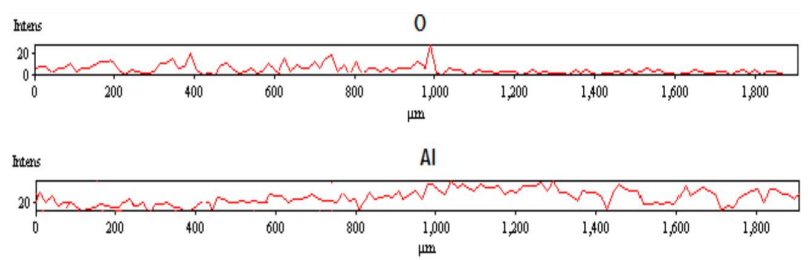

Fig. 7. Line scan EDS elemental analysis along the red arrow from Fig. 6.

\subsection{Hardness measurement}

In Fig. 8., Brinell hardness results are shown for each layer of FGM sample. Every layer has exhibited different hardness values. When the ratio of ceramic particles in the matrix increases, hardness value also increases. The hardness of Al 2124 alloy was lower than that of the produced functionally graded composite. The conducted study has shown that an FGM with 15 wt.\% alumina content was characterized by a larger hardness $(81 \mathrm{HB})$.

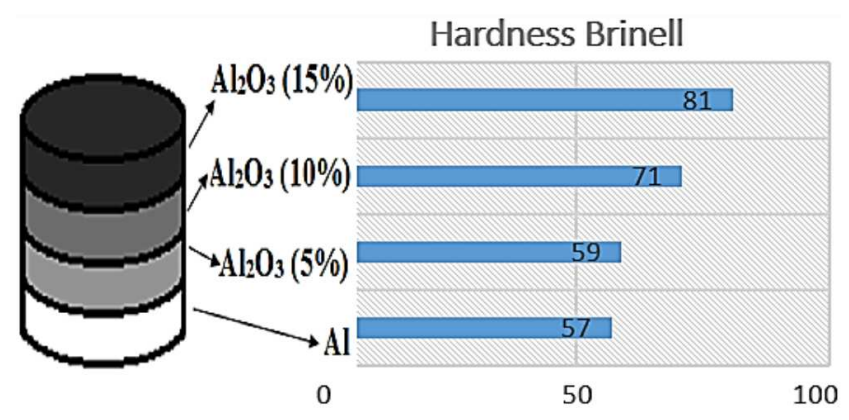

Fig. 8. Brinell hardness results for each layer of FGM sample.

\section{Conclusions}

In this study, PM method was applied to $\mathrm{Al} 2124 / \mathrm{Al}_{2} \mathrm{O}_{3}$ powders pair to obtain functionally graded composites. Functionally graded aluminum composite was successfully obtained in various compositions. Each of layers in the FGM has exhibited improved mechanical properties when compared with monolithic Al 2124 and has different hardness values. Thereby, every grade displayed different wear resistance, hardness, toughness etc. The key factor was the transition zone in FGM using PM. In the present work, the graded transition was achieved as seen in Fig. 6. Consequently, the functionally graded aluminum matrix composite can be varied in composition and structure gradually over volume, resulting in corresponding changes in the properties of the material. The produced FGM can be designed for specific application and functions.

\section{References}

[1] D. Garbiec, M. Jurczyk, N. Levintant-Zayonts, T. Mościcki, Arch. Civ. Mech. Eng. 15, 933 (2015).

[2] X. Zhu, J. Yu, X. Wang, Transactions of Nonferrous Metals Society of China 22, 1686 (2012).

[3] K. Konopka, M. Szafran, J. Mater. Proc. Technol. 175, 266 (2006).

[4] V. Laurent, C. Rado, N. Eustathopoulos, Mater. Sci. Eng. A 205, 1 (1996).

[5] M.S. EL-Wazery, A.R. EL-Desouky, Mater. Environ. Sci. 6, 1369 (2015).

[6] S. Suresh, A. Mortensen, Int. Mater. Rev. 42, 85 (1997).

[7] H. Izadi, A. Nolting, C. Munro, D.P. Bishop, K.P. Plucknett, A.P. Gerlich, J. Mater. Proc. Technol. 213, 1900 (2013).

[8] M.M. Rasheedat, T. Esther, M. Akinlabi, M. Shukla, S. Pityana, Proceedings of the World Congress on Engineering, Vol III, 2012, p. 2.

[9] T. Hirai, M. Sasaki, M. Niino, J. Japan Soc. Mater. Sci. 36, 1205 (1987).

[10] K.M. McHugha, Y. Linb, Y. Zhoub, S.B. Johnsonb, J.-P. Delplanque, E.J. Lavernia, Mater. Sci. Eng. A 477, 26 (2008).

[11] F. Piyadeh, H.P. Abdollah, M. Lieblich, Rev. Metal. 50, 1 (2014). 